\title{
Diffuse Idiopathic Skeletal Hyperostosis Causing Dysphagia: A Case Report
}

\author{
Ahmet Celal Iplikcioglu ${ }^{1}$ and Hamza Karabag ${ }^{2 *}$ \\ ${ }^{1}$ Department of Neurosurgery, Apex Cerrahi Tıp Merkezi, İstanbul, Turkey \\ ${ }^{2}$ Department of Neurosurgery, Harran Üniversity, Şanlıurfa, Turkey
}

${ }^{*}$ Corresponding author: Hamza Karabag, Department of Neurosurgery, Harran Üniversity, Şanlıurfa, Turkey, Tel: +905056843818; E-mail: hamzakarabag@yahoo.com

Received date: March 19, 2018; Accepted date: March 26, 2018; Published date: March 31, 2018

Citation: Iplikcioglu AC, Karabag H (2018) Diffuse Idiopathic Skeletal Hyperostosis Causing Dysphagia: A Case Report. J Clin Exp Orthop Vol 4.No1:55.

Copyright: (C2018 Iplikcioglu AC, et al. This is an open-access article distributed under the terms of the Creative Commons Attribution License, which permits unrestricted use, distribution, and reproduction in any medium, provided the original author and source are credited.

\section{Abstract}

Diffuse idiopathic skeletal hyperostosis is a noninflammatory systemic disease characterized by the osteophyte formation of vertebrae and ossification of various extraspinal ligaments. Although DISH is a relatively common disease, cervical involvement causing dysphagia is rare. In this report, we present such a case. The clinical features, diagnosis and the treatment of DISH are also discussed.

Keywords: Diffuse idiopathic skeletal hyperostosis (DISH); Disease; Dysphagia; Spine

\section{Introduction}

Diffuse idiopathic skeletal hyperosteosis (DISH) is a systemic non-inflammatory disease characterized by osteophytic calcification or ossification of the anterior longitudinal ligament of the spine and various extraspinal ligaments [1,2]. It occurs more frequently in males and elderly. Most of the cases are asymptomatic $[2,3]$.

In DISH, when cervical spine is involved cervical pain and restriction of neck movements due to the new bone formation are the main symptoms. However, cervical osteophytes rarely lead to disphagia, aspiration, airway obstruction related symptoms such as stridor, sleep apnea, hoarseness and difficult intubation [4-8]. Recently, Verlaan et al. reviewed the literature prior to 2009 and found 118 articles describing 204 patients with DISH related dysphagia and airway obstruction [4]. They also stated that DISH as a cause of disphagia and airway obstruction is still an increasing and overlooked condition. In this report, we present a case of DISH with cervical involvement and disphagia. The patient underwent excision of cervical osteophytes and showed a significant improvement in symptoms.

\section{Case Report}

A 60-year-old male was admitted to our clinic with the complaint of progressive difficulty in swallowing. He had no history trauma and systemic disease. He also had been examined by gastroenterology and otolaryngology departments and fibro-optic endoscopic examination had been performed.

Neurological and physical examinations were normal. Lateral cervical plain radiography showed cervical osteophytes and flowing ossification along the anterior aspects of the C2-C6 vertebral bodies (Figure 1a). Intervertebral disc spaces were spared and ankylosis of apophysial joints was absent. Cervical Magnetic resonance examination obtained to exclude intraspinal pathologies also revealed cervical osteophytes compressing the esophagus (Figure 1b).

Cervical osteophytes removed using high-speed air drill via anterior cervical approach. Discectomy and cervical stabilization were not performed. Postoperative period was uneventful. Postoperative plain radiography and computerized tomography scan showed successful removal of the cervical osteophytes (Figure $\mathbf{2 a}$ and $\mathbf{2 b}$ ). Difficulty in swallowing gradually improved. The patient was symptom free at last follow up examination 1 year after the operation.

\section{Discussion}

Clinical and radiological findings of DISH was first described by Forestier and Rotes-Querol in 1950 [2]. In 1975 Resnick et al. named the disease as DISH [9]. In the Dutch population older than 50 years, the prevalence of DISH diagnosed on chest radiography was $22.7 \%$ in males and $12.1 \%$ in females [3]. It is also obvious that its prevalence increases with older age, cardiovascular and metabolic problems [10]. Etiology of DISH is not clear, but it has been reported in association with many conditions such as acromegaly, obesity, diabetes mellitus, some infectious diseases, ankylosing spondylitis and hypervitaminosis A [7]. One-third of the patients are HLA B-27 positive. The cervical and thoracic spine frequently are affected. Focal and diffuse calcification and ossification of anterior longitudinal ligament are the main histopathological feature of the disease 
$[1,11]$. Sacroiliac and apophysial joints are not involved $[9,11]$ Additionally, enthesopathy of iliac crest, ischial tuberositios and trochanters major and spur formations of calcaneus and patella can be observed.

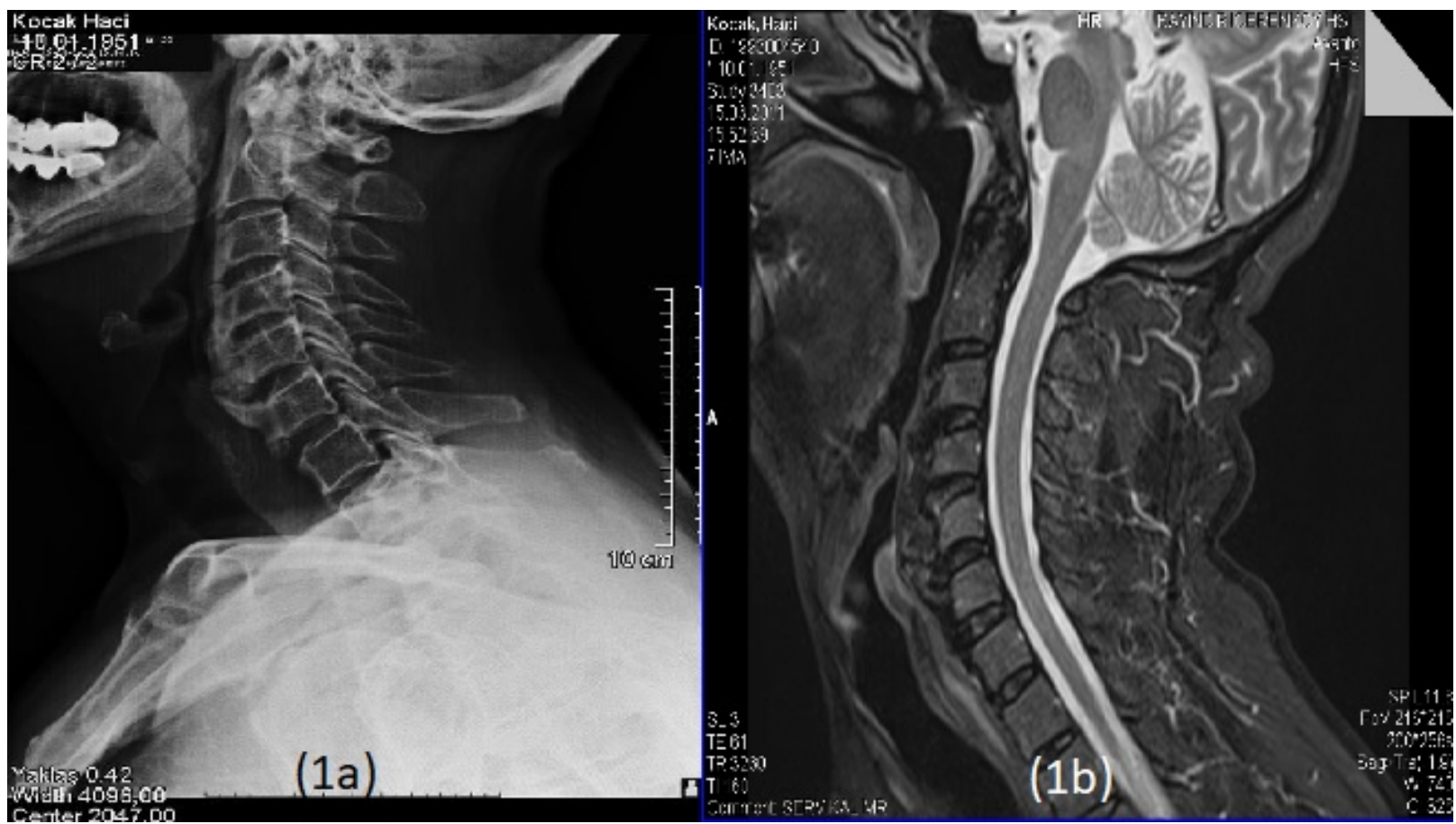

Figure 1: (a) Cervical lateral plain radiography, and (b) Cervical sagittal MRI show osteophytes and flowing ossification along the anterior aspect of vertebral bodies C2-C6. The disc heights are maintained and ankylosis in the apophyseal joints is absent. Compression of the esophagus by new bone formation is also noted.

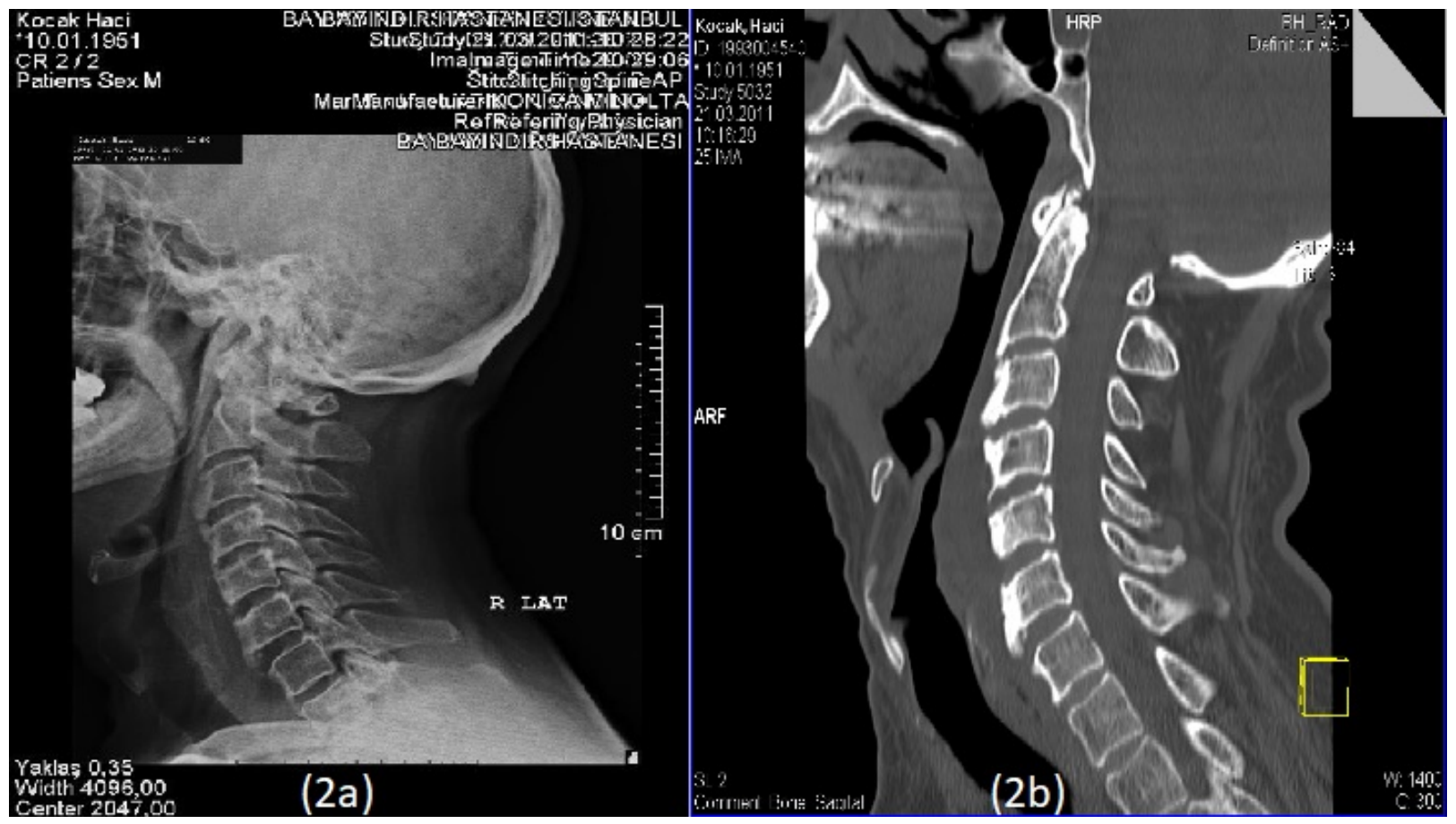

Figure 2: (a)Postoperative cervical lateral plain radiography, and (b) Sagittal reconstruction CT scan reveal the sufficient excision of the osteophytes. No spinal instability occurs.

The diagnosis can be established on the basis of radiologic examination. Presence of osteophytic calcification in four adjacent vertebrae, preservation of intervertebral disc height and absence of ankylosis in the interapophysial joints are the 
radiologic criteria for the diagnosis $[9,11]$. However, the localization of new bone formation differs according to the affected spinal region. Typical ossifications occur in the anterolateral part of the thoracic spine contralateral to the aorta with an appearance resembling flowing candle wax on plain lateral radiographies $[12,13]$. In contrast, hyperosteosis of the cervical spine is symmetrical and anterior to the vertebral bodies. In 1950, Forestier and Rotes Querol suggested that pulsating effect of vessels prevented the ossifications of soft tissues in DISH cases [2]. This theory was supported by several authors reporting that left sided thoracic ossifications were observed in the patients with situs inversus $[12,14]$. In the cervical region arteries are located lateral to the vertebral body therefore new bone formation is anterior and causes the displacement and compression of the esophagus and trachea.

Esophageal and tracheal compression due to cervical osteophytes is considered as the main reason of dysphagia, airway obstruction related symptoms and difficult intubation. However, some authors thought that esophageal fibrosis, inflammation of soft tissues, nerve entrapment, lesser mobile pharynx and food retention can play role in the development of dysphagia [7,13]. Barium swallowing study and esophagoscopy can be useful to determine the severity and the level of obstruction. In our case, we did not performed barium swallowing study because the previously performed esophagoscopy was unremarkable. In mildly symptomatic cases, conservative treatment using non-steroid anti-inflammatory drugs, myorelaxants, are recommended $[5,7]$. Surgical treatment should be considered in the cases with severe dysphagia, loss of weight and difficulty in breathing [4-7]. Excision of cervical osteophytes via anterior cervical approach is usually sufficient and discectomy and stabilization of vertebrae are not essential. The most important complications of surgery are laryngeal nerve injury, esophageal perforation and Horner syndrome [7].

Most of the patients treated by surgery show an improvement in symptoms, however, long term recurrences rate may be as high as $15-100 \%$ [15].

\section{References}

1. Mader R, Verlaan JJ, Buskila D (2013) Diffuse idiopathic skeletal hyperostosis: clinical features and pathogenetic mechanism. Nat Rev Rheumatol Rheumatol 9: 741-750.

2. Forestier J, Rotes-Querol J (1950) Senile ankylosing hyperostosis of the spine. Ann Rheum Dis 9: 321-330.
3. Westerveld LA, van Ufford HM, Verlaan JJ, Öner FC (2008) The prevelance of diffuse idiopatic skeletal hyperosteosis in an outpatient population in the Netherlands. J Rheumatol 35: 1635-1638.

4. Verlaan JJ, Boswijk PF, de Ru JA, Dhert WJ, Öner FC (2011) Diffuse idiopatic skeletal hyperosteosis of the cervical spine: An underestimated cause of dysphagia and airway obstruction. Spine J 11: 1058-1067.

5. Openlander ME, Orringer DA, LaMarca F (2009) Dysphagia due to anterior cervical hyperosteosis. Surg neural 72: 266-270.

6. Presutti L, Alicandri-Ciufelli M, Piccinini A, Trebbi M, Marchioni D, et al. (2010) Forestier disease: single-center surgical experience and brief literature review. Ann otol Rhinol laryngol 119: 602-608.

7. Karaaslan N, Gürbüz MS, çalışkan T, Şimşek AT (2017) Forestier syndrome presenting with dysphagia: case report of a rare presentation. J Spine Surgery 3: 723-726.

8. Thomson C, Moga R, Crosby ET (2010) Failed videolaryngoscape intubation in a patient with diffuse idiopatic skeletal hyperosteosis and spinal cord injury. Can J anaesth 57: 679-682.

9. Resnick D, Shaul SR, Robins JM (1975) Diffuse idiopathic skeletal hyperostosis (DISH): Forestier's disease with extraspinal manifestations. Radiology 115: 513-524.

10. Mader R, Lavi I (2009) Diabetes mellitus and hypertension as risk factors for early diffuse idiopatic skeletal hyperosteosis (DISH). Osteoarthr Cartil 17: 825-828.

11. Resnick D, Niwayama G (1976) Radiographic and pathologic features of spinal involvement in diffuse skeletal hyperosteosis (DISH). Radiolology 119: 559-568.

12. Verlaan JJ, Westerveld LA, Van keulen JW, Bleys RLAW, Dhert WJ, et al. (2011) Quantitative analysis of the anterolateral ossification mass in diffuse idiopatic skeletal hyperosteosis of the thoracic spine. Eur Spine J 20: 1474-1479.

13. Bakker JT, Kuperus JS, Kuijf HJ, Öner FC, de Jong PA, et al. (2017) Morphological characteristic of diffuse idiopatic skeletal hyperosteosis in the cervical spine. PLoS One 12: e0188414.

14. Carile L, Verdone F, Aiello A, Boungosto G (1989) Diffuse idiopatic hyperosteosis and situs viscerum inversus. J Rheomatol 16: 1120-1122.

15. Miyamoto $\mathrm{K}$, Sugiyama $\mathrm{S}$, Hosoe $\mathrm{H}$, linuma $\mathrm{N}$, Suzuki $\mathrm{Y}$, et al. (2009) Postsurgical recurrence of osteophytes causing dysphagia in patients with diffuse idiopathic skeletal hyperostosis. Eur Spine J 18: 1652-1658. 